\title{
O PARADIGMA DA COSMODERNIDADE: UMA ABORDAGEM TRANSDISCIPLINAR À EDUCAÇÃO PARA A CIDADANIA GLOBAL PROPOSTA PELA UNESCO
}

\author{
Javier Collado Ruano* \\ Dante Augusto Galeffi** \\ Roberto Leon Inacio Ponczek***
}

\begin{abstract}
RESUMO
O presente artigo tem como objeto de estudo refletir sobre a Educação para a Cidadania Global (GCE) proposta pela UNESCO na Agenda pós-2015 para o Desenvolvimento das Nações Unidas. Trata-se de uma pesquisa de triplo campo teórico-epistemológicometodológico que procura desenvolver uma consciência-identidade de "Terra-Pátria", na qual o ser humano seja visto como uma mesma espécie com uma mesma evolução, pois a história futura da humanidade precisa de uma evolução do conhecimento para novos conceitos dialéticos transculturais e trans-humanistas. Visando o entendimento e o respeito das caraterísticas histórico-culturais de cada comunidade, partimos do paradigma da cosmodernidade formulado por Nicolescu, da complexidade de Morin, e da polilógica de Galeffi para abordar o conhecimento através de uma epistemologia complexa, criativa, transdisciplinar, polissêmica, transcultural, transnacional e transpolítica, que promova a GCE como o principio de energia causal do processo de transformação do ser humano e da sociedade-mundo. Como resultado, propomos a criação de uma constelação de escolas-ONGs irmãs que desenvolvam projetos educativos altruístas de cooperação em todos os rincões do planeta para construir, em última instância, um novo horizonte transdemocrático na GCE proposta pela UNESCO para o século XXI.
\end{abstract}

Palavras-chave: Educação para a Cidadania Global. Cosmodernidade. Constelação de escolas-ONGs irmãs. Transdisciplinaridade. Transdemocracia.

\footnotetext{
*Diretor de Edição da Revista Global Education Magazine. Doutorando do Doutorado Multi-institucional e Multidisciplinar em Difusão do Conhecimento (DMMDC) da Universidade Federal da Bahia (UFBA), e doutorando em Filosofia da Universidade de Salamanca (Espanha). Endereço para correspondência: Universidade Federal da Bahia / Faculdade de Educação (FACED/ UFBA) - Doutorado em Difusão do Conhecimento. Av. Reitor Miguel Calmon - $\mathrm{s} / \mathrm{n}^{\mathrm{o}}$ - Vale do Canela - Salvador-BA - CEP 40110-100.dmmdc@ufba.br; javiercolladoruano@gmail.com

** Doutor em Educação (Filosofia da Educação) pela Universidade Federal da Bahia (UFBA). Professor Associado IV - DE (UFBA). Professor permanente do DMMDC. Coordenador do DMMDC (2009-2013). Endereço para correspondência: Universidade Federal da Bahia / Faculdade de Educação (FACED/UFBA) - Doutorado em Difusão do Conhecimento. Av. Reitor Miguel Calmon - s/n - Vale do Canela - Salvador-BA - CEP 40110-100. dgaleffi@uol.com.br; dmmdc@ufba.br

${ }_{* * *}$ Mestre em Física pela Pontifícia Universidade Católica do Rio de Janeiro (PUC-RJ). Doutor em Educação pela Universidade Federal da Bahia. Professor aposentado da UFBA. Professor permanente no Doutorado em Difusão do Conhecimento (DMMDC/ UFBA). Endereço para correspondência: Universidade Federal da Bahia / Faculdade de Educação (FACED/UFBA) - Doutorado em Difusão do Conhecimento. Av. Reitor Miguel Calmon - s/n - Vale do Canela - Salvador-BA - CEP 40110-100. dgaleffi@ uol.com.br; ponczek@ufba.br; dmmdc@ufba.br
} 


\section{ABSTRACT}

\section{THE COSMODERNITY PARADIGM: A TRANSDISCIPLINARYAPPROACH TO THE GLOBAL CITIZENSHIP EDUCATION PROPOSED BY UNESCO}

The nature of this paper is to study and reflect upon the Global Citizenship Education (GCE) proposed by UNESCO in the post-2015 Development Agenda led by the United Nations. It is a research presented by a triumverate made up of epistemologicaltheoretical-methodological field that seeks to develop anidentity-consciousness of "Earth-Homeland", where human beings are seen as a same biological species with the same evolution, because the future history of humanity requires evolution of knowledge towards new transcultural and transhumanism dialectical concepts. Toward an understanding and respect for the historic-cultural characteristics of each community, we start from the Cosmodernity paradigm formulated by Nicolescu, the complexity of Morin and the poli-logic of Galeffi in order toto approach knowledge through a complex, creative, transdisciplinary, polysemous, transcultural, transnational and transpolitical epistemology that promotes GCE as the causal energy principle of the transformation process of human being and the world-society. As a result, we propose the creation of a Constellation of Twinned NGO-Schools which develop altruistic educational cooperation projects in all corners of the planet to build, ultimately, a new trans democratic horizon in the GCE proposed by UNESCO for the twenty-first Century.

Keywords: Global Citizenship Education. Cosmodernity. Constellation of Twinned NGOs-schools. Transdiciplinarity. Transdemocracy.

\section{Introdução}

O motivo principal do presente trabalho é refletir sobre o ponto de não retorno alcançado pela espécie humana em sua evolução histórica. Desde a metade do século XX, e pela primeira vez na história conhecida da humanidade, o ser humano tem a potencialidade tecnológico-nuclear de destruir tudo o que lhe rodeia. Nesta linha de acontecimentos, a emergente sociedade-mundo do século XXI necessita criar e construir metapontos de vista para o favorecimento do encontro entre as diferentes culturas e civilizações coexistentes no planeta, com o intuito de criar possibilidades de sustentabilidade para todos os povos. Diante disso, abordaremos a discussão da "Educação para a Cidadania Global"1 iniciada pela UNESCO, utilizando uma metodologia transdisciplinar com a intencionalidade de pensar o problema transnacional e transcultural

1 Global Citizenship Education ou Educação para a Cidadania Global tem como sigla GCE tradução em inglês que será utilizada em todo o texto. de salvaguardar o gênero humano a partir de um campo intencional centrado na conjugação de uma tríplice área da condição humana: epistemológica, política e educativa. Para tal fim, nos apoiaremos na Teoria da Complexidade para desenvolver a compreensão multirreferencial da interdependência universal da própria vida no planeta Terra.

Desse modo, intencionamos criar pontos de fuga para a construção de novas discussões filosóficas sobre a complexidade dos problemas globais da humanidade do terceiro milênio. Propomos também um marco educativo transdisciplinar, transnacional e transcultural com a intencionalidade de estimular o desenvolvimento de uma nova sociedade humana trieticamente sustentável, ou seja, uma sociedade curadora da ética ambiental, social e mental (espiritual) simultaneamente. Trata-se de uma proposta epistemológica, política e educativa que requer olhar para o futuro numa perspectiva polilógica ${ }^{2}$

\footnotetext{
2 A perspectiva polilógica, segundo Galeffi (2001), compreende a coexistência de múltiplas lógicas no processamento do conhecimento humano, reunindo diferentes planos de constituição do Real sem a
} 
que se abre para o que Nicolescu (2014) chama de consciência cosmoderna, afirmando a substituição do objeto epistemológico pela relação, a interação e a interconexão dos fenômenos naturais, entendendo os fenômenos como uma totalidade, ou seja, como uma matriz cósmica extensa em que tudo se encontra em movimento perpétuo e estruturando-se energeticamente, confirmando que esta unidade do mundo não é estática, implicando a diferenciação, a diversidade e a contradição. A consciência cosmoderna concebida por Nicolescu se harmoniza, por um lado, com o que Galeffi (2013a) chamou de emergência triética planetária, compreendendo a insustentabilidade atual da vida humana ambiental, social e mental; e por outro lado, com a unidade do indivíduo-sociedade-espécie proposta por Morin em "O Método" (2001, 2002a, 2002b, 2002c, 2003, 2005).

\section{O que é a Global Citizenship Education (GCE)?}

No mês de dezembro de 2013, a UNESCO promoveu o I Fórum Internacional com o título "Global Citizenship Education: Preparing learners for the challenge of the 21st Century", em Bangkok, Tailândia. O Fórum, organizado em apoio à campanha lançada pelo Secretário Geral das Nações Unidas, Ban Ki-moon, a Global Education First Initiative (GEFI) reuniu pessoas de diferentes governos, parceiros de desenvolvimento e da sociedade civil, assim como pesquisadores da academia. O propósito era esclarecer as ações da perspectiva emergente nas áreas políticas, de pesquisa e da prática educativa. Como resultado dos debates e das discussões técnicas sobre a GCE, a UNES$\mathrm{CO}$ formulou o documento "Global Citizenship Education: An Emerging Perspective" (UNITED NATIONS EDUCATIONAL, SCIENTIFIC AND CULTURAL ORGANIZATION, 2013), no qual foram elaboradas perspectivas comuns emergentes da consulta das três questões, a saber: Porque cidadania global e GCE agora? O que é GCE?

$\mathrm{O}$ que tem que ser feito no nível global para apoiar e promover a GCE?

redução monológica a um único plano de Realidade, como ocorre no racionalismo moderno ocidental.
Perspectivas comuns que, longe de formularem respostas mágicas para o futuro comum da sociedade-mundo, representam uma oportunidade aberta para uma visão transnacional e transcultural de maneira que as novas gerações possam se tornar "cidadãs do mundo". A GCE instiga-nos a desenvolver uma consciência cosmoderna que compreenda a dignidade e a liberdade do ser humano na sua conjuntura planetária e cósmica. $\mathrm{O}$ surgimento do ser humano na Terra é só mais um instante do universo. Somos seres ecodependentes, com uma dupla identidade: uma própria, que nos distingue, e outra de interdependência ao ambiente. Um ambiente constituído por todos os seres que nele vivem.

Uma consciência cosmoderna que julgamos complementar ao ponto 2.1.2 do documento da UNESCO já mencionado neste texto:

Em todos os casos, a cidadania global não implica um status jurídico. Refere-se mais a um sentimento de pertencimento à comunidade global e a humanidade comum, com os seus supostos membros experimentando a solidariedade e a identidade coletiva entre si e a responsabilidade coletiva em nível global. A cidadania global pode ser vista como um ethos / metáfora, ao invés de um compromisso formal. (UNITED NATIONS EDUCATIONAL, SCIENTIFIC AND CULTURAL ORGANIZATION, 2013, p. 3, tradução nossa).

A GCE se propõe a contribuir para o esclarecimento da cidadania global sem perder de vista as diferentes culturas do planeta, evitando uma homogeneização de uma ideia de cidadania global que atenda apenas a uma minoria e não a todos, como é sua proposição. Considerando a própria vida na sua complexidade como o foco para todos na construção de um sentido de cidadania global que atenda ao principio da alteridade, do respeito mútuo, da amorosidade compartilhada pelo principio da diferença e não apenas da identidade, que contemple dialogicamente a contradição implícita dos fenômenos. A educação precisa promover $o$ desenvolvimento dos sentimentos de pertença e de compreensão da totalidade vivente. As pessoas precisam sentir-se cidadãs do mundo em uma perspectiva de cosmodania, ou seja, numa relação com a totalidade conjuntural ser humano-natureza (GALEFFI, 2013a). 
O processo de aquisição do conhecimento humano é uma relação dialógica significativa entre o saber e o fazer, mediada pela consciência do indivíduo. Deste modo, o passado e o futuro estão presentes no processo de pesquisa espiritual e/ou científica, sendo indagações complementares de uma realidade comum conformada pela totalidade indivisa entre a consciência e a matéria.

Trata-se, portanto, de organizar o conhecimento numa perspectiva transdisciplinar, transnacional e transcultural que vislumbre a unidade da atual civilização planetária, caracterizada pela consciência de uma cidadania global portadora de infinita diversidade cultural em um mundo finito. Metaforicamente, a humanidade é uma unidade transorgânica em contínuo processo evolutivo, em que seus indivíduos têm que florescer com os mesmos cuidados que uma criança requisita. Uma criança que representa a semente que simboliza a beleza da singularidade em sua novidade radical, sendo a imagem do transdisciplinar, pois nela reside a totalidade de possibilidades culturalmente diferentes.

Seguindo os pontos 2.2.1 e 2.2.2 do documento que aborda os objetivos da GCE, parece-nos que a GCE poderia representar a abertura da metáfora evocada:

Objetivo: A Educação para a Cidadania Global tem como intenção empoderar os aprendentes a participarem e assumirem papéis ativos tanto locais como globais para enfrentarem e resolverem os desafios globais e, finalmente, se tornarem colaboradores pró-ativos para um mundo mais justo, pacífico, tolerante, inclusivo, seguro e sustentável.

A Educação para a Cidadania Global é transformativa, dando aos aprendentes a oportunidade e as competências para realizarem seus direitos e obrigações para a promoção de um mundo melhor e futuro. Baseia-se na aprendizagem de outros processos educativos transformadores, incluindo a educação em direitos humanos, educação para a sustentabilidade, educação para a compreensão internacional/intercultural e educação para a paz. (UNITED NATIONS EDUCATIONAL, SCIENTIFIC AND CULTURAL ORGANIZATION, 2013, p. 3, tradução nossa).

Desse modo, para um bom cultivo dessas sementes de gerações futuras é imprescindível que a GCE promova o desenvolvimento de uma nova consciência-identidade-diferença humana ao modo de uma criança, baseada em uma concepção pluralista e polilógica do agir ético inspirador de novos horizontes transnacionais e transculturais no processo de construção multidimensional da sociedade-mundo interdependente atual e futura. Para isto é necessária a modelagem de uma atitude transdisciplinar cujos horizontes epistemológicos estejam abertos à natureza ontológica do amor como dialógica da espécie humana. A semente do amor representa, neste sentido, o fenômeno ecológico de ação vital para alcançar uma compreensão ética e solidária entre o próprio gênero humano. Esta consideração supõe, efetivamente, a formação de autênticos mundólogos e mundólogas, expressões inspiradas no escritor argentino Ernesto Sábato, que utilizou a expressão mundólogos exprimindo a urgente necessidade da sociedade de contar com pessoas que estejam atentas aos problemas mais urgentes e globais. Assim, inspirado em Sábato, Edgar Morin, Emilio-Roger Ciurana e Raúl Motta (2003) afirmam que a educação planetária deve propiciar uma mundologia da vida cotidiana.

\section{A metodologia transdisciplinar: rumo ao paradigma da cosmodernidade}

Nos albores do terceiro milênio, a compreensão da condição humana necessita de uma contextualização adequada e pertinente, pois as partículas atômicas que compõem a vida no nosso planeta e que nos compõem nasceram nos primeiros segundos do cosmos, os nossos átomos de carbono se criaram em um sol anterior ao nosso sol, e as nossas moléculas se formaram na Terra (MORIN, 2011). A espécie humana é uma entidade cosmo-bio-genética procedente de uma mesma evolução galáctica pós Big-Bang cujo futuro devir está interligado no espaço-tempo. Deste modo, a coevolução do ser humano com o universo requer uma nova metodologia, fora do pensamento positivista dos séculos XIX e XX, que reduz e separa o sujeito do objeto.

Essa nova metodologia é necessariamente abrangente, holística, polilógica e transdimensional, compreendendo o ser humano como parte integrante de uma totalidade cósmica autopoética. Neste sentido, os três pilares da metodologia trans- 
disciplinar formulados por Nicolescu (2010) são paradigmáticos: 1 . Há na natureza e na sociedade diferentes níveis de Realidade e de percepção; 2 . A passagem de um nível de Realidade para outro se dá pela lógica do terceiro incluído; 3 . A teoria da complexidade. Estes pilares representam uma nova abordagem epistemológica multidimensional e multirreferencial, uma ecologia transdisciplinar que está lançada na aventura indefinida e infinita do conhecimento humano, complexo e aberto à criação radicalmente nova.

O complexo desafio de construir uma cidadania global é um problema que ultrapassa a essência do gênero humano e, portanto, requer uma tripla reforma: epistemológica, política e educativa. Refletir sobre o valor e a significação da GCE na era globalizada do século XXI exige abordar as dinâmicas mundiais (econômicas, políticas, culturais, sociais, educativas etc.) com uma visão holística e transnacional que proponha alternativas criativas de mudança. Para fazer esta "leitura do mundo", é preciso começar a observar a sua complexidade, multidimensionalidade e interdependência, compreendendo a educação como um processo em contínua expansão, como o próprio universo (COLLADO RUANO; GALEFFI, 2012a).

Contudo, como criar um programa educativo mundial, como a GCE, que respeite as características histórico-culturais definidoras de cada comunidade sem homogeneizar e sem alienar? Como preparar para a democracia e para uma cidadania global crítica e responsável em escolas que não ensinam a tomar decisões transnacionais e transculturais? Será possível desenvolver uma consciência planetária de comum-responsabilidade para alcançar um desenvolvimento sustentável presente e futuro? Aprenderemos a conviver na unidade/diversidade humana para evitarmos a autodestruição durante o terceiro milênio? Responder a essas questões relativas à GCE exige-nos uma profunda mudança nas estruturas de construção do pensamento e uma nova organização do conhecimento, em que os Direitos Humanos suponham um metaponto de vista articulador do esforço humano de tomar consciência da sustentabilidade ética da sociedade-mundo, a qual requer uma epistemologia complexa, criativa, transversal, polissêmica, transpolítica e transcultural (GALEFFI, 2013a).
Portanto, evidencia-se a necessidade de tomar consciência da consciência e consciência da inconsciência (LUPASCO, 1994) sobre a interdependência universal da sociedade-mundo atual para desenvolver uma nova consciência-identidade-diferença de "Terra-Pátria", expressão usada por Morin (2011), onde a educação seja entendida como um processo global de conscientização e de reconstrução cultural da sociedade-mundo. Desse modo, dado que o microcosmo escolar encarna o macrocosmo das estruturas sociais, o futuro da humanidade requer uma tripla reforma epistemológica, política e educativa, que faça frente às dinâmicas técno-economicistas globalizadoras, e cuja convergência suponha uma transformação radical na direção da vida inteligente e curadora de seu poder-ser mais próprio.

Trata-se de um desafio de talante mundial que, como vimos, requer uma nova consciência-identidade-diferença comum, cuja perspectiva trans-humanista perceba polilogicamente os diferentes níveis de Realidade que compõem o mundo e o cosmos conhecido humanamente. Do mesmo modo que a própria ontologia estrutura a natureza em diferentes níveis de Realidade, o ser humano tem diferentes estratos, níveis e planos de percepção gnoseológica que estruturam e concretizam a sua complexidade histórica no seu contexto cosmológico. Portanto, o problema presente de refletir sobre a harmonização da Terra-Pátria, como horizonte pacífico e trans-histórico comum supõe o complexo desafio de desenvolver o conhecimento transdisciplinarmente para propiciar novas concepções transnacionais e transculturais dialógicas capazes de prever futuros conflitos e alcançar um desenvolvimento sustentável global, para o todo da vida. Com palavras de Nicolescu (2014, p. 14, tradução nossa):

O instante presente é, estritamente falando, um não tempo, uma experiência de relação entre o Sujeito e o Objeto; então, contem potencialmente nele mesmo, o passado e o futuro, um fluxo total de informação e um fluxo total de consciência, que ultrapassa os diferentes níveis de Realidade. O tempo presente é verdadeiramente a origem do futuro e a origem do passado. Diferentes culturas, presentes e futuras, desenvolvem-se no tempo histórico, o qual é o tempo de mudança no estado de ser das pessoas e das 
nações. A transculturalidade concerne ao tempo presente em uma trans-história, uma noção introduzida por Mircea Eliade, que concerne ao impensável e à epifania. A transculturalidade é a condição necessária para a existência da cultura.

É nessa visão cosmoderna da transculturalidade que reside a complexidade da construção e modelagem da formação humana através da proposta GCE. Uma complexidade que deve partir da polilógica tri-identitária que identifique os diferentes níveis de Realidade e de percepção do indivíduo-sociedade-espécie, visando realizar uma teoriação transformadora do mundo no presente e no futuro comum da humanidade. Para compreender melhor a polilógica tri-identitária, temos que aplicar a lógica do terceiro incluído, matematicamente formalizada por Stephane Lupasco.

\section{A transdemocracia: um novo horizonte político para o futuro?}

Sem dúvida, um dos maiores desafios da futura GCE será o processo de encaminhar a humanidade para novas formas de cooperação e organização social democrática, que integrem a diversidade cultural como uma fonte de riqueza, assim como relações justas e ecologicamente sustentáveis com o meio ambiente. $\mathrm{Na}$ atualidade, há um consenso universal em considerar a democracia como a única alternativa política para que as sociedades plurais em desenvolvimento possam garantir o direito inalienável de todo ser humano. Mas que outra forma de governo poderia ser a alternativa para uma política libertadora das sociedades humanas do estado atual de ignorância, pobreza, de indigência social, submissão simbólica e interdição ontológica? Faz-se necessário reinventar a democracia? Caberia já pensar em uma transdemocracia?

Com estas questões, procura-se imaginar o que poderia ser um regime político transdemocrático, sem a perda dos princípios orientadores da democracia ideal e real historicamente constituída. $\mathrm{Na}$ sua gênese histórica grega, démokratía é kratía, a força, o poder do "dêmos", do "povo". Aqui o sentido de "povo" é imediatamente ligado a "poder". "Demos" é um derivado de dynamis, o "poder". Portanto, a démokratía grega se pode traduzir de modo provocante como "povo de poder", caracte- rizando-se como forma de governança baseada na decisão de uma maioria simples entre aqueles que são investidos de poder em determinado território povoado. A palavra "povo", então, é ambígua na cultura grega, porque não diz respeito a todo ser humano natural de um determinado lugar ou território, mas aos poderosos de um determinado agrupamento humano. Então, no horizonte cultural grego, a democracia é uma forma de poder de uma determinada classe dominante, em parte aristocrática e em parte comerciante e rica. Uma forma de poder que não realiza os ideais modernos e iluministas de igualdade, liberdade e fraternidade (GALEFFI, 2013b).

A democracia de origem grega foi deixada para trás em sua consumação histórica na Atenas de Péricles, porque na afirmação dos Direitos Humanos Universais encontra-se presente a aspiração cristã pela fraternidade universal. A aspiração democrática pela fraternidade universal é, sem ambiguidade, um traço evidente do cristianismo em sua aspiração de amor ao todo da humanidade. A fraternidade, assim, seria um apelo afetivo fundamental para a construção de sociedades democráticas livres, igualitárias, cujo fim seria conduzirem-se no amor ao divino, a si mesmos e aos outros (GALEFFI, 2013b).

De qualquer modo, todo regime político denominado democrático tem a sua soberania fundada no poder do povo que o sustenta, um povo que deve, por direito, ser instruído para exercer plenamente a sua soberania. Entretanto, como conciliar no seio dos regimes democráticos vigentes em muitos países do mundo o estado de pobreza e desigualdade social gritante existente entre seres humanos ontologicamente iguais? Como uma democracia plena pode admitir a desigualdade entre os seres humanos? Por que muitas sociedades democráticas não alcançam o êxito erradicando a pobreza e a miséria? Não alcançam simplesmente porque os seus indivíduos não realizaram em si mesmos a liberdade, a igualdade e a fraternidade. Então, os regimes democráticos vigentes não dão conta da tarefa premente de superação dos horizontes de um processo civilizatório marcado por desigualdades humanas gritantes, sendo preciso reunir forças transnacionais e transculturais para arquitetar e construir alternativas garantidoras de repúblicas 
curadoras do ser humano em todos os seus momentos existenciais, universalmente falando.

A menos que se queira admitir que o imperativo ético da igualdade entre os seres humanos seja meramente retórico, apenas servindo de ardil para esconder os verdadeiros intuitos de uma suposta minoria governante, é preciso projetar novos constructos sociais que garantam o direito de todo ser humano por uma vida livre, igual e fraternal. Entretanto a tríade da revolução francesa que se incorpora plenamente nos ideais democráticos das Repúblicas modernas permaneceu apenas no plano ideal, porque o próprio ser humano, em suas formulações capitalistas, parece lutar para que a democracia universal permaneça sendo uma quimera e uma efabulação apenas útil para manter a submissão involuntária das massas humanas ignaras de seu poder-ser mais próprio. De fato, toda forma democrática de governo atualmente existente configura-se na dimensão política de uma cidadania global sustentada por estados de direito fundados no poder econômico concentrado nas mãos de uma minoria, o que propriamente se pode denominar de poder oligárquico ou plutocrático, mesmo quando este poder econômico esteja em mãos de grandes corporações multinacionais ou de governos como G7, G8, G20 etc.

É uma evidência como ainda não alcançamos o estado de democracia plena, o que elevaria a humanidade ao pleno exercício dos seus direitos universais fundados no ethos da fraternidade entre todos os seres humanos do planeta. Apareceria, então, a transdemocracia em sua forma plena: a aspiração humana pelo alcance do estado de direito universal por meio de uma racionalidade polilógica, uma racionalidade garantidora do estado de direito à liberdade e imprevisibilidade dos acontecimentos migratórios transculturais e transnacionais que caracterizam o ser humano desde a sua aparição no planeta Terra.

Todavia, como alcançar o estado de plena atualidade dos direitos universais da pessoa humana quando ainda há os poucos que governam e os muitos que são governados? Como empoderar a cidadania global para que se torne o poder de lutar por seus direitos básicos e por sua dignidade humana? Como é possível que os nossos jovens conheçam os dorsais dos futebolistas, mas não os artigos dos direitos humanos ou da sua constituição nacional? Qual é a verdadeira potencialidade da GCE para transgredir o atual paradigma da ignorância global?

Seguramente, estamos diante de um verdadeiro salto de natureza na ordem política do mundo globalizado. Um salto de natureza que implica, efetivamente, uma profunda transformação triética do indivíduo-sociedade-espécie: mental-espiritual, social-planetária e cósmica-ambiental. Uma emergência triética que decorre do acelerado progresso tecnocientífico e telemático global, e que requer um novo tipo de auto-eco-organização epistemológica, política e educativa para criar consciências cosmodernas na cidadania global atual e futura. Neste sentido, a proposta da constelação de escolas-ONGs irmãs tem que se entender como um fenômeno convergente dentro do marco heterotópico ${ }^{3}$ criado pelos movimentos altermundistas do Fórum Social Mundial, a Rainbow Gathering, os YoungOs, os princípios éticos da declaração da Carta da Terra etc.

\section{A Constelação de Escolas-ONGs Irmãs: uma proposta utópica para a GCE da UNESCO?}

Citando o item 1.1.3 do mencionado documento da UNESCO, "há uma oportunidade clara para incluir uma referência à GCE na agenda pós-2015 de desenvolvimento como parte de conhecimento, habilidades e competências que os aprendentes requerem no século XXI e além" (UNITED NATIONS EDUCATIONAL, SCIENTIFIC AND CULTURAL ORGANIZATION, 2013, p. 2, tradução nossa). A GCE não só tem que ser incluída na agenda para o desenvolvimento pós-2015, como tem que ser vista como um fenômeno da própria condição humana que ultrapasse transversalmente as futuras metas do milênio das Nações Unidas. A GCE não pode ser considerada um conceito ou expressão de moda entre a academia, a sociedade civil ou os governos, pois isso significa a introdução de pequenas alterações nos conteúdos curriculares das escolas, sem contribuir na mudança de para-

3 Em ciências políticas, heterotopia é um conceito elaborado pelo filósofo Michel Focault para descrever a coexistência de diferentes utopias que funcionam sem hegemonia alguma no mesmo tempo e espaço. 
digma que a sociedade-mundo do terceiro milênio está reclamando. Um bom exemplo seria a presente década batizada pela UNESCO como a Educação para o Desenvolvimento Sustentável (2005-2014). Se for certo que a sua intencionalidade tem mobilizado milhões de pessoas ao redor do mundo para caminhar nesta direção, o fracasso se fez patente na incapacidade de determinar e concretizar acordos comuns por parte dos representantes de governo que participaram da Conferência de Desenvolvimento Sustentável das Nações Unidas, conhecida como Rio+20, em 2012.

A GCE não tem que encontrar solução para os problemas cada vez mais complexos que surgem no atual sistema de referência econômico da sociedade-mundo. A GCE deveria promover a mudança do próprio sistema de referência capitalista, introduzindo uma compreensão polilógica que abarque a dialógica entre os fenômenos micro-locais-simples e os macro-globais-complexos. Portanto, temos que observar a GCE através de estímulos criativos que surjam do complexo contexto planetário atual, e que sirvam para reestruturar transversalmente $o$ futuro do nosso mundo diante do devir da humanidade como espécie. E esta concepção transnacional e transcultural da educação implica uma ruptura radical com as estruturas político-econômicas e socioeducativas do passado, pois não existe dúvida de que a educação tecnocrática, ainda vigente, é a consequência do modelo de organização social alienante que o capitalismo tem imposto, após a Revolução Industrial, para reduzir os estudantes a consumidores submissos e a cidadãos passivos (COLLADO; GALEFFI, 2012b).

O que se pretende com a proposição da constelação de escolas-ONGs irmãs é estabelecer uma alternativa que possa contribuir na criação de uma rede virtual de conscientização para a cidadania global. Contudo, como criar espaços virtuais/ atuais que possam apoiar a liderança dos jovens e que possam constituir soluções eficazes para a formulação de uma GCE verdadeiramente transformadora da crise econômica, epistemológica, política, educativa e humana atual? Como formular propostas que suponham novas simbioses transculturais e transnacionais dentro da diversidade da civilização planetária atual? Como desenvolver uma atitude trans-humanista que permita compre- ender a polilógica tri-identitária dos diferentes níveis de Realidade gnoseológica que constituem o indivíduo-sociedade-espécie?

Evidentemente, responder essas perguntas representa um desafio antropológico, social e político a um só tempo, que haverá de ser abordado desde uma nova cosmovisão filosófica e geopolítica que dê uma ênfase especial à interdependência indissociável das dimensões locais-globais e globais-locais. Uma nova cosmovisão que compreenda que todo dogma, ideologia política e teoria materialista (como o capitalismo, o marxismo, o nazismo, o estalinismo etc.) devastaram o século XX por causa da estrutura lineal do pensamento fundamentado em um único nível de Realidade, derivado da física clássica, pois achavam que estavam de posse da totalidade e, portanto, da verdade absoluta.

Por esse motivo, a nossa proposta da constelação de escolas-ONGs irmãs, baseada na Teoria da Complexidade, procura aprofundar nos avanços da física quântica, na cosmologia quântica, e da biologia molecular para desenvolver uma consciência cosmoderna que permita identificar a pluralidade da diversidade cultural como uma fonte de riqueza do único "estado-nação" legítimo do ser humano: o planeta Terra.

Para tal fim, podemos lembrar o nascimento das Nações Unidas no seu contexto histórico com o problema de salvaguardar a sociedade-mundo da autodestruição nuclear. Desde a metade do século $\mathrm{XX}$ a humanidade entraria em um novo estágio civilizatório que nos exige o esforço metacognitivo de compreender a diferença do outro. Deste modo, a GCE proposta pela UNESCO teria que vislumbrar as Nações Unidas como a totalidade de um sistema complexo: a Terra. Um sistema complexo composto por uma teia de interligações dos 193 estados membros ${ }^{4}$ (mais a Palestina e a Santa Sé como convidados): econômica, cultural, política, religiosa etc. Estados membros interdependentes que estão interligados pelos sete princípios da complexidade definidos por Morin (2011): sistêmico ou organizacional, o hologramático, do círculo retroativo, do círculo recursivo, da auto-

4 Devemos mencionar que existem 243 países, dos quais 193 são Estados Membros nas Nações Unidas e os demais se encontram em situação de independência não reconhecida internacionalmente ou de dependência em relação a outros países. 
-eco-organização (autonomia e dependência), o dialógico e da reintrodução do conhecimento em todo conhecimento.

Nessa percepção da Teoria da Complexidade, a proposta de uma constelação de escolas-ONGs irmãs baseia-se, por um lado, na reinterpretação do conceito de cidades irmãs. Um conceito que tem como objetivo criar laços de cooperação, essencialmente nas relações econômicas e culturais, entre duas cidades de áreas geográficas distintas, as quais costumam ter características semelhantes. Então, tratar-se-ia de estender o conceito de cidades irmãs ao campo educativo, criando novas redes virtuais/ atuais entre as escolas de todo o mundo. E, por outro lado, a proposta também estaria baseada no caráter catalizador, filantrópico e humanista que as organizações sem fins lucrativos (sejam ONGs, associações culturais, fundações etc.) trazem ao processo de conscientização das novas gerações para dotar-lhes de criticidade, sensibilidade, autonomia e liderança.

Imaginemos agora que as partes do nosso sistema complexo, ou seja, os países integrantes das Nações Unidas fizessem o esforço de enviar uma lista de suas escolas nacionais para uma instituição neutra de caráter supranacional como a própria UNESCO. Uma lista ou base de dados que, a priori, já estaria pronta na grande maioria dos países altamente burocratizados. Imaginemos que antes disso as subpartes que compõem estas partes do nosso sistema complexo, ou seja, as partículas que denominaremos de escolas, fizessem o esforço de enviar uma descrição detalhada das suas características definidoras (número de estudantes, línguas que são aprendidas, status público ou privado, problemáticas próprias etc.), na qual estivessem incluídas também as informações relativas à sua cidade, bairro ou comunidade em que estão inseridas e das quais fazem parte os seus estudantes-cidadãos (como, por exemplo, a situação geográfica, demografia, clima etc.).

Imaginemos agora que no nível local fossem criadas organizações sem fins lucrativos entre os vizinhos da sua comunidade, onde caberiam pessoas de todas as idades, assim como os campos da educação formal e informal. Imaginemos também que essas organizações comunais formassem pequenos núcleos políticos para desenvolver uma ativa participação cidadã sobre as problemáticas locais/regionais/nacionais/globais. Imaginemos que cada escola-ONG tivesse o sua próprio web site para ser consultado na base de dados comum da UNESCO, para facilitar as livres interconexões entre elas mesmas. Seria possível que os próprios discentes explicassem as festividades e os costumes dos seus povos a outros estudantes, para compreender melhor as diferencias culturais desde crianças? Poderia isso ajudar a compreender melhor as diferenças culturais e as situações reais de cada comunidade, evitando a "contaminação" das mídias controladas pelos grupos de poder econômico? É possível imaginar tal processo em um nível transdismensional que ultrapasse o âmbito macroglobal e microlocal ao mesmo tempo?

Olhemos agora a sociedade-mundo atual astronomicamente, como já fizeram as civilizações antigas, chinesas, hindus, incas, pré-colombianas etc. Vislumbremos a sociedade-mundo como uma galáxia composta por um conjunto de planetas, com os seus satélites; com cometas e meteoroides; estrelas e matéria interestelar; a matéria escura; as nuvens de gás e o próprio pó cósmico. Todos eles são corpos celestes unidos pela mesma força gravitacional, que denominaremos de UNESCO no nosso sistema complexo. Imaginemos que as comunidades locais formam sistemas solares em que as escolas são as estrelas e no entorno delas giram planetas de diversas índoles como organizações culturais, partidos políticos, associações religiosas etc. Imaginemos, então, que a GCE proposta pela UNESCO agrupasse milhões de estrelas (escolas-ONGs) em constelações (irmanamentos), criando uma grande base de dados virtual no Espaço-Tempo Cibernético (ETC). Constelações responsáveis pela realização de projetos de cooperação e desenvolvimento nas microssituações de emergência local-global, com o objetivo de repercutir nas estruturas emergentes das problemáticas macroglobais. Dito de outra forma, a soma das ações politico-educativas no nível local-global terminariam modificando entropicamente as tendências globais-locais do processo de homogeneização derivado das estruturas técno-econômicas da globalização

Em essência, a constelação de escolas-ONGs irmãs não só representaria um Espaço-Tempo Cibernético (ETC) transcultural e transnacional, 
tratando problemáticas globais como a erradicação da pobreza, o desenvolvimento sustentável ou a confraternização humana; seria também transdisciplinar, pois quando se trata de música, arte, literatura, filosofia e pensamento, a mundialização cultural não tende à homogeneidade; ao contrário, as culturas do mundo inteiro se fecundam entre elas engendrando filhos e filhas planetárias. Neste sentido, refletir sobre a GCE supõe olhar a unidade transcendental do indivíduo-sociedade-espécie - a unitas multiplex - através dos três eixos transdisciplinares propostos durante o II Congresso Mundial sobre a Transdisciplinaridade: atitude transdisciplinar, pesquisa transdisciplinar e ação transdisciplinar. Ou seja, pesquisas ou currículos transdisciplinares cuja pluralidade epistemológica introduza a atitude transdisciplinar de construir uma grande família humana - fundamentada nos princípios de justiça e solidariedade - e que derive em última instância na ação transdisciplinar do ser humano: propondo a articulação da formação em relação ao mundo (eco-formação) com outras pessoas (hetero e coformação), consigo mesmo (autoformação), como ser (ontoformação), assim como com o conhecimento formal e não formal. Em palavras de Nicolescu (2008, p. 92): "O Espaço-Tempo Cibernético não é nem determinista nem indeterminista. Ele é o espaço de escolha humana. $\mathrm{Na}$ medida em que o ETC permite que a noção de níveis de Realidade e da lógica do terceiro incluído seja colocada em jogo, ele é potencialmente um espaço transcultural, transnacional e transpolítico."

Para nós, esse seria o verdadeiro "tesouro a descobrir" pela educação, que o político francês Jacques Delors refletia no final do século XX: a aposta da GCE através da criação de um Espaço Tempo Cibernético transnacional, transcultural, transpolítico, transreligioso e trans-humaista que engendrasse filhos e filhas planetárias (COLLADO RUANO, 2013). Um ETC que identifique polilogicamente os diferentes níveis de Realidade que compõem a tri-identidade do indivíduo-sociedade-espécie, como indivíduo de uma comunidade local específica, como cidadão de uma sociedade determinada pertencente a um estado/nação e como uma mesma espécie cosmo-bio-genética em constante processo de evolução. Uma identidade aberta à diversidade infinita da cidadania global. Em outras palavras, uma tri-identidade transcultural e transnacional que atue em prol do alcance de uma convivência pacífica e transdemocrática durante o terceiro milênio: construindo um autêntico e revolucionário movimento de cidadania global.

\section{Conclusões}

O objetivo principal da proposta de constelações de escolas-ONGs irmãs é criar um novo modelo teórico transdisciplinar, transcultural e transnacional que possa contribuir ao debate aberto para a implementação da GCE na agenda pós-2015.

Obviamente, refletir na proposta de constelações de escolas-ONGs irmãs traz muitos questionamentos. Neste sentido, o conceito tem que ser compreendido como um projeto conscientizador em construção, aberto a reinterpretações, complementações e considerações, pois o seu objetivo é humanizar a ação educativa por meio de novos compassos pedagógicos que componham as melodias pacíficas do século XXI e além. Melodias harmoniosas de metamorfose social, individual e antropológica, que deverão estar baseadas no fundamento polifônico-trans-humanista para alcançar um novo estágio humano, mais altruísta e ecologicamente sustentável.

Não existem dúvidas que a sociedade-mundo deverá desenvolver novas sinergias multidimensionais de caráter global para alcançar o cumprimento das futuras metas do milênio da agenda pós-2015 das Nações Unidas, pois são metas sistêmicas, interligadas e interdependentes: como as conexões neuronais dos nossos cérebros. Consequentemente, devemos contextualizar as metas através de uma consciência cosmoderna, baseada na polilógica tri-identitaria do indivíduo-sociedade-espécie, para identificar a sociedade-mundo como uma totalidade integrada, e não como a soma das suas partes dissociadas entre si. Uma mudança epistemológica, política, educativa e espiritual, cujo enfoque transdisciplinar, transpolítico, transcultural e transreligioso esteja baseado simultaneamente na pluralidade e na unidade da atual emergência planetária da sociedade do conhecimento, o que corresponde à comum-responsabilidade de todos com todos. Portanto, a humanidade deve promover novas redes educativas de cooperação altruísta no 
ETC que simbolizem uma orquestra sinfónica divulgadora da paz mundial. Internet não é só uma variável a mais no famoso Índice de Desenvolvimento Humano, representa um elemento emergente que permite reestruturar e reformular a complexidade dos problemas globais encontrados nos albores do terceiro milênio.

É preciso, então, que a GCE crie uma estratégia de educação global no ETC que atue como um novo padrão transcultural e transnacional tri-identitário. Fazendo um paralelo com o passado, a GCE tem que utilizar o ETC com a mesma potencialidade que a comunidade protestante fez com a imprensa para reestruturar as ideias sacras no século XVI, pois o ETC simboliza um autêntico universo transdemocrático para propor reflexões criativas que suponham soluções efetivas nesta conjuntura histórica que Edgar Morin (2003) denominou como "a idade de pedra da civilização planetária". Portanto, o conceito da constelação de escolas-ONGs irmãs terá que ser interpretado como uma ferramenta pré-histórica para que a civilização planetária possa começar a escrever conjuntamente a sua trans-história neste início de milênio. A história é feita por todos nós, e por isso todos nós temos que escrevê-la conjuntamente e sem hierarquizações culturais no espaço-tempo. O Espaço Tempo Cibernético representa, efetivamente, o nível de Realidade propício para desenvolver o paradigma da cosmodernidade baseado na aceitação, na compreensão e na superposição da diversidade cultural.

Tratar-se-ia, em essência, de reconceitualizar as escolas e a sua função social de construção psicológica das futuras gerações cidadãs. Para isso teríamos que empoderar as escolas, salvando-as da deriva academicista e trasladando-as à esfera da realidade social mundial. Portanto, a nossa proposição da constelação de escolas-ONGs irmãs tem a intencionalidade de ajudar a ampliar o horizonte aberto da GCE, com o objetivo de criar e desenvolver projetos educativos altruístas de cooperação em todos os rincões da Terra-Pátria.

Diante do exposto, temos que refletir e tomar consciência da responsabilidade de construir, hoje, a sociedade-mundo de amanhã. Uma sociedade-mundo que terá que se organizar internacionalmente, de forma pacífica e não violenta, como uma autêntica orquestra sinfônica de galáxias-escolas interconectadas, pois delas dependerá a verdadeira práxis política-educativa transformadora do mundo. Portanto, é preciso entrever o futuro para estarmos preparados quando ele chegar, pois não existe dúvida de que os computadores quânticos, a inteligência artificial, a nanotecnologia, as lentes de contato com aceso à internet, a mutação genética do DNA e as viagens no espaço modificarão radicalmente os nossos hábitos em um curto período de tempo: contextualizando o gênero humano no paradigma da cosmodernidade. Talvez fosse uma boa ideia começar a mudar o sistema de referência compreendendo que a atual sociedade-mundo não é um presente dos nossos pais e mães, mas um empréstimo dos nossos filhos e filhas. E o que acharão as futuras gerações dos seus pais e avôs se não fizerem tudo o que estiver em suas mãos para melhorar e salvaguardar a sociedade-mundo? Seguramente nada de promissor para o futuro da vida em nosso modesto planeta nos espera caso não se faça o esforço criador para mudar o rumo do desenvolvimento humano global. E daí a emergência de uma educação para a cidadania global.

\section{REFERÊNCIAS}

COLLADO RUANO, Javier. The Planetary Cybernetic Intelligence: A Transhumanist and Transcultural Democratic Territory. Global Education Magazine, set. 2013. Disponível em: < http://www.globaleducationmagazine. com/planetary-cybernetic-intelligence-transhumanist-transcultural-democratic-territory/>. Acesso em: 4 abr. 2014.

COLLADO RUANO, Javier; GALEFFI, Dante A. Educación Global: un marco teórico-epistemológico complejo y transdisciplinar para una educación filantrópica y planetaria. In: FÓRUM INTERNACIONAL DE INNOVACIÓN Y CREATIVIDAD, 6., 2012a, Barcelona. Anais... Barcelona: Universidad de Barcelona, 2012a. Comunicado.

A metodologia construtivista da Educação Global para alcançar uma aprendizagem significativa

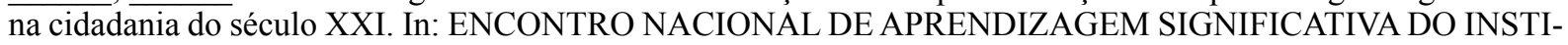


TUTO OSWALDO CRUZ, 4., Garanhuns, PE. Anais... Garanhuns, PE: Universidade Federal de Rio Grande do Sul/ Universidade de Pernambuco, 2012b. Comunicado.

GALEFFI, Dante A. Ética e complexidade: a emergência triêtica planetária. In: SALLES, João Carlos; AZEVÊDO, Eliane S. Salvador (Orgs). Academia de Ciências da Bahia. Salvador: Academia de Ciências da Bahia, 2013a. p. 65-116.

O ser-sendo da Filosofia. Salvador: Edufba, 2001.

Questões acerca da transdemocracia ou multidocracia na sociedade telemática contemporânea. Global Education Magazine, set. 2013b. Edição especial. Disponível em: <http://www.globaleducationmagazine.com/ questoes-acerca-da-transdemocracia-ou-multidocracia-na-sociedade-telematica-contemporanea/ $>$. Acesso em: 4 abr. 2014.

LUPASCO, Stéphane. O homem e suas três éticas. Tradução de Armando Pereira da Silva. Lisboa: Instituto Piaget, 1994.

MORIN, Edgar. O Método I - A natureza da natureza. Porto Alegre: Sulina, 2003.

. O Método 2 - A vida da vida. Porto Alegre: Sulina, 2001.

. O Método 3 - O conhecimento do conhecimento. Porto Alegre: Sulina, 2002a.

. O Método 4 - As idéias: habitat, vida, costumes, organização. Porto Alegre: Sulina, 2002b.

O Método 5 - A humanidade da humanidade: a identidade humana. Porto Alegre: Sulina, 2002c.

O Método 6 - A Ética. Porto Alegre: Sulina, 2005.

La vía para el futuro de la humanidad. Barcelona: Paidós, 2011.

MORIN, Edgar; CIURANA, Emilio-Roger; MOTTA, Raúl. Educar na era planetária. O pensamento complexo como método de aprendizagem no erro e na incerteza humana. São Paulo: Cortez, 2003.

NICOLESCU, Basarab. O manifesto da transdisciplinaridade. São Paulo: Triom, 2008.

Methodology of Transdisciplinarity-Levels of Reality, Logic of the Included Middle and Complexity. Transdisciplinary Journal of Engineering \& Science, v 1, The ATLAS, p. 17-32, 2010.

From Modernity to Cosmodernity. Science, Culture, and Spirituality. New York: State University of New York Press, 2014.

UNITED NATIONS EDUCATIONAL, SCIENTIFIC AND CULTURAL ORGANIZATION (UNESCO). Global Citizenship Education: An Emerging Perspective. Bangkok, Tailândia, 2013. Disponível em: <http://unesdoc. unesco.org/images/0022/002241/224115e.pdf >. Acesso em: 4 abr. 2014.

Recebido em: 07.04.2014

Aprovado em: 26.09.2014 